\title{
Inhibitory Effects of BST406, a Newly Synthesized Benzylideneacetophenone Derivative, on Abnormal Vascular Smooth Muscle Cell Proliferation
}

\author{
Tack-Joong KIM, ${ }^{*, a}$ Hyeong-Jun Han,,${ }^{b, \#}$ Yong-Jae Kim, ${ }^{a}$ Jae-Chul Jung, ${ }^{c}$ Ji-Yeon YU, ${ }^{d}$ \\ Jung-Jin LEE, ${ }^{e}$ and Yeo-Pyo YuN ${ }^{b}$ \\ ${ }^{a}$ Division of Biological Science and Technology, College of Science and Technology, Yonsei University; Wonju 220-710, \\ Korea: ${ }^{b}$ College of Pharmacy, Chungbuk National University; Cheongju 361-763, Korea: ${ }^{c}$ Department of Medicinal \\ Chemistry, School of Pharmacy, University of Mississippi; P.O. Box 1848, University, MS 38677-1848, U.S.A.: ${ }^{d}$ Institute \\ for Molecular Biology and Genetics, Chonbuk National University; Jeonju 561-756, Korea: and ${ }^{e}$ College of Pharmacy, \\ Chungnam National University; Daejeon 305-764, Korea.
}

Received August 12, 2009; accepted January 28, 2010; published online February 23, 2010

\begin{abstract}
Benzylideneacetophenone analogues are known to have several significant biological activities, including antiinflammatory, antitumor, antibacterial, antiviral, and gastric-protective activities. However, the antiproliferative effects of benzylideneacetophenone analogues on vascular smooth muscle cells (VSMCs) are unknown. The aim of this study was to elucidate the antiproliferative effects and molecular mechanism of BST406, a newly synthesized benzylideneacetophenone derivative, on platelet-derived growth factor (PDGF)-BB-stimulated rat aortic VSMCs. BST406 inhibited $\left[{ }^{3} \mathrm{H}\right]$-thymidine incorporation into DNA in VSMCs following treatment with PDGFBB $25 \mathrm{ng} / \mathrm{ml}$. PDGF-BB-stimulated DNA synthesis was significantly reduced. Moreover, pretreatment with BST406 $(0-10 \mu \mathrm{M})$ suppressed the proliferation of PDGF-BB-stimulated cells in a concentration-dependent manner. We also investigated the mechanism of the antiproliferative effects of BST406 in PDGF-BB-stimulated VSMCs. In Western blot analysis, PDGF-BB-stimulated $(25 \mathrm{ng} / \mathrm{ml})$ phospholipase-C (PLC) $\gamma 1$ and Akt phosphorylation was inhibited by BST406 $(0-10 \mu \mathrm{M})$. However, BST406 did not inhibit the PDGF-receptor $\beta$-chain $(\mathrm{PDGF}-\mathrm{R} \beta)$ and extracellular-regulated kinase 1 and 2 (ERK1/2) phosphorylation induced by PDGF-BB. To confirm that the inhibitory effects of BST406 are mediated through the inhibition of PLC $\gamma 1$ or Akt, the effects of inhibitors on cell viability were examined. U73122 completely inhibited PDGF-BB-induced proliferation of VSMCs. However, LY294002 $10 \mu_{\mathrm{M}}$ had no significant effects on PDGF-BB-induced proliferation. These findings suggest that the inhibitory effects of BST406 on the proliferation of PDGF-BB-stimulated VSMCs are mediated by suppression of the PLC $\gamma 1$ signaling pathways. Our observations may explain, in part, the mechanistic basis for the prevention of cardiovascular disease (such as atherosclerosis and restenosis after coronary angioplasty) by BST406.
\end{abstract}

Key words platelet-derived growth factor; cardiovascular disease; BST406; benzylideneacetophenone analogue

Cardiovascular disease is associated with a multitude of pathophysiologic conditions, including vascular smooth muscle cell (VSMC) proliferation in response to vessel injury. ${ }^{1)}$ One of the principal regulators of mitogenesis in VSMCs is platelet-derived growth factor (PDGF)-BB, and it has been observed that PDGF-BB expression is increased in atherosclerotic lesions. In addition, an association between PDGF and VSMC proliferation has been demonstrated in animal experiments in which increases in PDGF-BB after arterial injury were found to be correlated with neointimal cellular proliferation. ${ }^{2,3)}$

The PDGF-BB-induced mitogenesis signaling pathway has been relatively well characterized. The binding of PDGFBB to PDGF receptor (PDGF-R) leads to phosphorylation of the PDGF-receptor $\beta$-chain (PDGF-R $\beta$ ) tyrosine residues. This activated PDGF-R $\beta$ is associated with a number of $\mathrm{SH} 2$ domain-containing proteins, including phospholipase-C (PLC) $\gamma 1 .{ }^{4)}$ Extracellular-regulated kinases 1 and 2 (ERK1/2) and Akt are major signal-transducing molecules involved in the regulation of cellular proliferation, differentiation, and apoptosis $^{5}$; their activation is known to be associated with the development and progression of proliferative cardiovascular disease, such as hypertension and atherosclerosis. ${ }^{5-7}$ Therefore an understanding of the role of inhibition of these pathways in preventing PDGF-BB-stimulated VSMC proliferation is important in terms of developing methods for treating cardiovascular disease.

* To whom correspondence should be addressed. e-mail: ktj@yonsei.ac.kr \# Equal contribution with first author.
Benzylideneacetophenone analogues have several significant biological activities, including antiinflammatory, ${ }^{8)}$ antitumor, ${ }^{9-11)}$ antibacterial, ${ }^{12)}$ antiviral, ${ }^{13)}$ and gastric-protective activities. ${ }^{14)}$ Recently, these compounds have been shown to have considerable effects on free radical scavenging, suppression of lipopolysaccharide (LPS)-induced nitric oxide (NO) generation, and cytotoxicity in microglia. ${ }^{15)}$ The effects of benzylideneacetophenone analogues on VSMC proliferation have not been reported.

In this study, we aimed to elucidate the antiproliferative effect and molecular mechanism of BST406, a newly synthesized benzylideneacetophenone derivative, in PDGF-BBstimulated signaling pathways in VSMCs.

\section{MATERIALS AND METHODS}

Materials Cell culture materials were purchased from Gibco-BRL (Gaithersburg, MD, U.S.A.). Phospho-ERK1/2, phospho-Akt, phospho-PLC $\gamma 1$, phospho-PDGF-R $\beta$, and LY294002 were purchased from Cell Signaling Technology (Danvers, MA, U.S.A.). PDGF-BB was obtained from Koma Biotechnology (Seoul, Korea). U73122 was purchased from Calbiochem (San Diego, CA, U.S.A.). BST406 was synthesized by Dr. Jae-Chul Jung (University of Mississippi). ${ }^{15}$ The other chemicals used were of the highest analytical grade commercially available.

Culture of Rat Aortic VSMCs Rat aortic VSMCs were 
obtained from BioBud Co., Ltd. (Seoul, Korea). Cells were cultured in Dulbecco's modified Eagle's medium (DMEM) supplemented with $10 \%$ fetal bovine serum (FBS), penicillin $100 \mathrm{U} / \mathrm{ml}$, streptomycin $100 \mu \mathrm{g} / \mathrm{ml}, N$-(2-hydroxyethyl)piperazine- $N^{\prime}$-2-ethanesulfonic acid (HEPES) $8 \mathrm{~mm}$, and L-glutamine $2 \mathrm{~mm}$ at $37^{\circ} \mathrm{C}$ in a humidified $5 \% \mathrm{CO}_{2}$ incubator. The purity of VSMC cultures was confirmed by immunocytochemical localization of $\alpha$-smooth muscle actin. VSMCs between passages 4 and 8 were used in this experiment.

Cell Proliferation and $\left[{ }^{3} \mathrm{H}\right]$-Thymidine Incorporation Assays Rat aortic VSMCs were seeded into 12-well culture plates at $1 \times 10^{5}$ cells $/ \mathrm{ml}$ and cultured in DMEM containing $10 \% \mathrm{FBS}$ at $37{ }^{\circ} \mathrm{C}$ for $24 \mathrm{~h}$ until $70 \%$ confluent. Media was then replaced with serum-free medium containing BST406. Cells were stimulated with PDGF-BB $25 \mathrm{ng} / \mathrm{ml}$, trypsinized with trypsin-ethylenediaminetetraacetic acid (EDTA), and counted using a hemocytometer. For $\left[{ }^{3} \mathrm{H}\right]$-thymidine incorporation experiments, VSMCs were seeded in 24-well culture plates under the above conditions, and $2 \mu \mathrm{Ci} / \mathrm{ml}$ of $\left[{ }^{3} \mathrm{H}\right]-$ thymidine was added to the medium for $4 \mathrm{~h}$. Reactions were terminated by aspirating the medium and washing the cultures with phosphate-buffered saline (PBS) containing 10\% trichloroacetic acid and ethanol/ether $(1: 1, \mathrm{v} / \mathrm{v})$. The acid-insoluble $\left[{ }^{3} \mathrm{H}\right]$-thymidine was extracted into $0.5 \mathrm{M} \mathrm{NaOH}$ $250 \mu \mathrm{l} /$ well, and this solution was then mixed with $3 \mathrm{ml}$ of scintillation cocktail (Ultimagold, Packard Bioscience, Meriden, CT, U.S.A.) and analyzed using a liquid scintillation counter (LS3801, Beckman, Düsseldorf, Germany). Protein contents were determined in 50- $\mu$ l aliquots of residual solution using BCA Protein Assay Reagent Kits (Pierce Biotechnology, Rockford, IL, U.S.A.). For cell viability experiments, VSMCs were precultured in serum-free medium in the presence or absence of BST406 for $24 \mathrm{~h}$ and stimulated with PDGF-BB $25 \mathrm{ng} / \mathrm{ml}$. After $23 \mathrm{~h}$, an EZ-Cytox cell viability assay kit (Daeil Lab., Seoul, Korea) was added to the medium, and the cells were incubated for $1 \mathrm{~h}$. The optical density was determined at $450 \mathrm{~nm}$ using a microplate reader (BioTek Instruments Inc., Winooski, VT, U.S.A.).

Western Blot Analysis Sodium dodecyl sulfate-polyacrylamide gel electrophoresis (SDS-PAGE) was performed on cell lysates using 7.5-10\% acrylamide gels according to the method described by Ahn et al. ${ }^{16)}$ Proteins were transferred to polyvinylidene difluoride (PVDF) membranes (BioRad, Hercules, CA, U.S.A.), which were then blocked overnight at $4{ }^{\circ} \mathrm{C}$ in Tris-buffered saline containing $0.1 \%$ Tween $20(\mathrm{TBS} / \mathrm{T})$ and 5\% skim milk powder. Membranes were then incubated with a 1:2000 dilution of phosphoERK1/2, phospho-Akt, phospho-PLC $\gamma 1$, and phosphoPDGF-R $\beta$ antibodies. Blots were washed with TBS/T and then incubated with a $1: 5000$ dilution of horseradish peroxidase-conjugated anti-rabbit immunoglobulin $\mathrm{G}$ ( $\mathrm{IgG}$ ) antibody (Cell Signaling Technology). Proteins were detected using an enhanced chemiluminescence (ECL) Western blotting detection reagent (GE Healthcare, Buckinghamshire, U.K.).

Statistical Analysis Experimental results are expressed as mean \pm S.D. One-way ANOVA followed by Dunnett's test was used for multiple comparisons. $p$ values of $<0.05$ and $<0.01$ were considered to represent statistically significant differences.

\section{RESULTS}

Effects of BST406 on PDGF-BB-Stimulated DNA Synthesis and Proliferation of VSMCs PDGF-BB is an important VSMC mitogen and is thought to mediate phenotypic modulation of VSMC proliferation. ${ }^{17-19)}$ To determine whether BST406, a newly synthesized benzylideneacetophenone derivative (Fig. 1A), inhibits PDGF-BB-stimulated VSMC proliferation, we assessed the effect of BST406 on DNA synthesis, cell proliferation, and cell viability. The antiproliferative activity of BST406 was assessed using a $\left[{ }^{3} \mathrm{H}\right]-$ thymidine incorporation assay. VSMCs were precultured in the presence of BST406 $(0-10 \mu \mathrm{M})$ in serum-depleted medium for $24 \mathrm{~h}$, followed by stimulation with PDGF-BB $25 \mathrm{ng} / \mathrm{ml}$ for $24 \mathrm{~h}$. As shown in Fig. 1B, BST406 reduced PDGF-BB-induced $\left[{ }^{3} \mathrm{H}\right]$-thymidine incorporation in a concentration-dependent manner. Significant inhibition of $\left[{ }^{3} \mathrm{H}\right]-$ thymidine incorporation after PDGF-BB stimulation was observed at BST406 $1 \mu_{\mathrm{M}}(18.80 \%), 3 \mu \mathrm{M}(35.32 \%), 5 \mu \mathrm{M}$ $(43.85 \%)$, and $10 \mu \mathrm{M}(80.34 \%)$. We also assessed the inhibitory effects of BST406 by direct cell counting. Pretreatment with BST406 decreased the total number of cells following PDGF-BB stimulation in a concentration-dependent manner, with inhibition of $38.55 \%, 48.30 \%, 69.71 \%$, and $84.93 \%$ at concentrations of $1,3,5$, and $10 \mu \mathrm{M}$, respectively (Fig. 2A). Furthermore, PDGF-BB-stimulated cell viability was potently inhibited by BST406 (Fig. 2B). Since antiproliferation is often accompanied by cytotoxicity, we also measured the cytotoxic effects of BST406 on VSMCs and found no evidence of cytotoxicity at $10 \mu \mathrm{M}$ (data not shown). Therefore, our results indicate that BST406 inhibits PDGF-BBinduced VSMC proliferation without cytotoxicity.

A
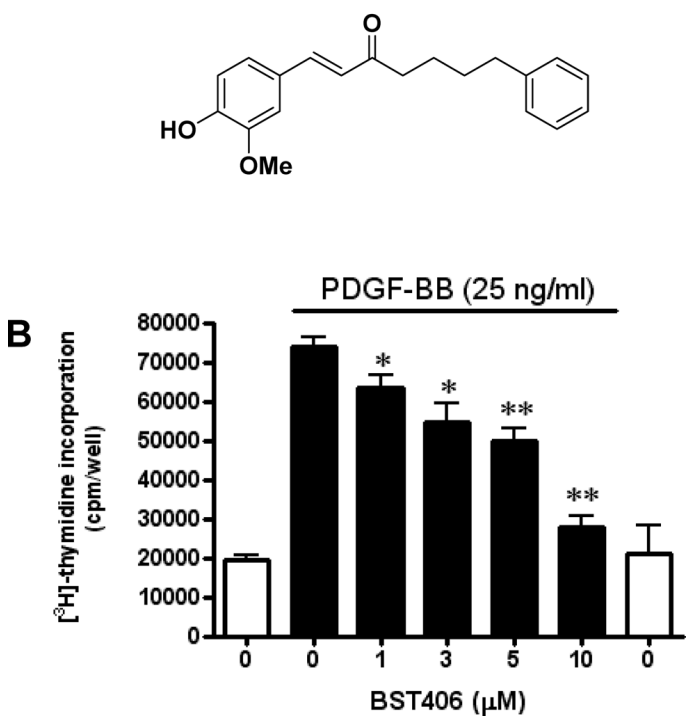

Fig. 1. Effects of BST406 on PDGF-BB-Stimulated $\left[{ }^{3} \mathrm{H}\right]$-Thymidine Uptake in VSMCs

(A) Chemical structure of BST406, a newly synthesized benzylideneacetophenone derivative. (B) Cells were precultured in serum-free medium in the presence or absence of BST406 $(0-10 \mu \mathrm{M})$ for $24 \mathrm{~h}$, followed by stimulation with PDGF-BB $25 \mathrm{ng} / \mathrm{ml} \mathrm{for}$ $20 \mathrm{~h}$. $\left[{ }^{3} \mathrm{H}\right]$-thymidine $(2 \mu \mathrm{Ci} / \mathrm{ml})$ was added to the medium, and cells were incubated for $4 \mathrm{~h}$. Radioactivity was measured using a liquid scintillation counter. Values represent mean \pm S.D. from three separate assays. $* p<0.05, * * p<0.01$ compared with PDGF-BB alone. 
A

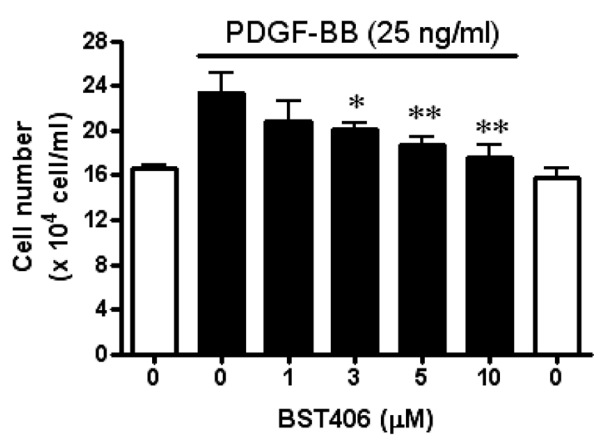

B

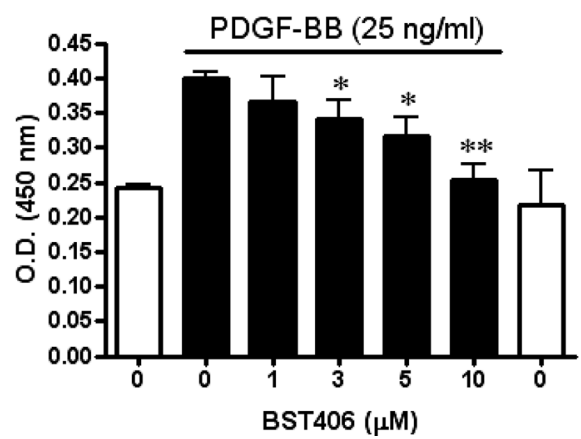

Fig. 2. Effects of BST406 on PDGF-BB-Stimulated Proliferation of VSMCs

(A) Effects of BST406 on the number of VSMCs following stimulation with PDGFBB. Cells were precultured in serum-free medium in the presence or absence of BST406 $(0-10 \mu \mathrm{M})$ for $24 \mathrm{~h}$ and then stimulated with PDGF-BB $25 \mathrm{ng} / \mathrm{ml}$ for $24 \mathrm{~h}$. Cells were trypsinized and counted with a hemocytometer. (B) Effects of BST406 on the viability of VSMCs stimulated with PDGF-BB. Cells were precultured in serumfree medium in the presence or absence of BST406 $(0-10 \mu \mathrm{M})$ for $24 \mathrm{~h}$ and then stimulated with PDGF-BB $25 \mathrm{ng} / \mathrm{ml}$. After $23 \mathrm{~h}$, an Ez-Cytox kit was added to the medium, and the cells were incubated for $1 \mathrm{~h}$. The optical density was determined at $450 \mathrm{~nm}$ using a microplate reader. Values represent mean \pm S.D. from three different assays. $* p<0.05, * * p<0.01$ compared with PDGF-BB alone.

Effects of BST406 on PDGF-R $\beta$, PLC $\gamma 1$, Akt, and ERK1/2 Phosphorylation in PDGF-BB-Stimulated VSMCs PDGF-BB binding to the PDGF receptor leads to the activation of several intracellular signaling cascades. ${ }^{18-20}$ Therefore we hypothesized that the antiproliferative properties of BST406 were due to modulation of the signaling cascade involved in VSMC proliferation. The inhibitory effects of BST406 on PDGF-R $\beta$, ERK1/2, PLC $\gamma 1$, and Akt phosphorylation levels were examined using Western blotting. VSMCs were precultured in the presence or absence of BST406 $(0-10 \mu \mathrm{M})$ in serum-free medium for $24 \mathrm{~h}$ and then stimulated for $1-20 \mathrm{~min}$ with PDGF-BB $25 \mathrm{ng} / \mathrm{ml}$. As shown in Fig. 3, PDGF-BB-stimulated PDGF-R $\beta$ and ERK1/2 phosphorylation did not decrease at concentrations of BST406 1, 3, 5, and $10 \mu \mathrm{M}$, respectively. However, PLC $\gamma 1$ and Akt phosphorylation was significantly inhibited by BST406 $(0-10 \mu \mathrm{M})$ in a concentration-dependent manner.

Effects of Inhibitors on the Proliferation of PDGF-BBStimulated VSMCs To confirm that the inhibitory effects of BST406 are mediated through the inhibition of PLC $\gamma 1$ or Akt, the effects of several inhibitors on cell viability were examined after treating VSMCs with $10 \mu \mathrm{M}$ of LY294002 (a PI3K inhibitor) or $10 \mu \mathrm{M}$ of U73122 (a PLC $\gamma 1$ inhibitor) for 5 h. U73122 completely inhibited PDGF-BB-induced proliferation of VSMCs. However, LY294002 had no significant effect on PDGF-BB-induced proliferation at $10 \mu \mathrm{M}$ (Fig. 4).

\section{DISCUSSION}

The proliferation of VSMCs is known to be involved in a broad spectrum of cardiovascular disorders. ${ }^{21)}$ This can be triggered by various extracellular mitogenic stimuli (such as PDGF-BB, angiotensin II, and insulin) that activate a variety of signaling events involved in the regulation of cell growth and division. ${ }^{22-24)}$ In the present study, we investigated the antiproliferative activity of BST406 and the related effects on signal transduction in cultured VSMCs. In $\left[{ }^{3} \mathrm{H}\right]$-thymidine incorporation, cell proliferation, and cell viability experiments, our results showed that BST406 inhibits the proliferation of VSMCs in a dose-dependent manner following stimulation with PDGF-BB $25 \mathrm{ng} / \mathrm{ml}$ (Figs. 1B, 2). However, the antiproliferative effects of BST406 were not due to the induction of cytotoxicity (data not shown). Therefore our results indicate that BST406 induces inhibition of PDGF-BBinduced VSMC proliferation without cytotoxicity.

The induction of cell proliferation is a highly regulated process and can be promoted by PDGF-BB. ${ }^{17,25)}$ The receptor tyrosine kinases for PDGF-BB activate PLC $\gamma 1$, phosphatidyl inositol 3 (PI3)-kinase, and mitogen activated protein (MAP) kinase, and their signaling pathways are important in early intracellular mitogenic signal transduction for cell growth and survival. ${ }^{26)}$ The current study found that BST406 suppresses abnormal proliferation in the presence of PDGF-BB in vitro. We observed that the antiproliferative properties of BST406 were due to modulation of the signaling cascade involved in VSMC proliferation. Phosphorylation of PLC $\gamma 1$, ERK1/2, and Akt kinase was induced by PDGF-BB; treatment with BST406 inhibited PDGF-BB-induced phosphorylation of PLC $\gamma 1$ and Akt but not that of ERK1/2. Several groups reported that the MAPK signaling pathway is critical in the abnormal proliferation of VSMCs, which have been shown to be activated in response to balloon overstretch injury in porcine carotid arteries. ${ }^{727)}$ PLC $\gamma 1$ signaling mediates a central downstream signal transduction route for various growth factors, including PDGF-BB. ${ }^{4}$ PI3-kinase positively regulates cell survival. Akt, a serine/threonine protein kinase, is activated through the PI3-kinase pathway. ${ }^{24,28)}$ These kinases have each been implicated in VSMC proliferation and cell survival. ${ }^{28,29)}$ Studies using PDGF-R $\beta$ inhibitor have shown reduced VSMC proliferation in vitro and prevention of cardiovascular problems. ${ }^{24,29-32)}$ However, we found that the antiproliferative effects of BST406 were not due to inhibition of ERK1/2 or PDGF-R $\beta$ phosphorylation, indicating that $\mathrm{PLC} \gamma 1$ and Akt protein (or upstream proteins) are potential targets of BST406 (Fig. 3). We next examined whether the inhibitory effects of BST406 were observed following blockade of PLC $\gamma 1$ or Akt. As shown in Fig. 4, LY294002 $10 \mu \mathrm{M}$ did not inhibit PDGF-BB-stimulated VSMC proliferation. These data indicate that PLC $\gamma 1$ may be a potential target of the antiproliferative activity of BST406. At present, the molecular mechanism by which BST406 exerts its effects on VSMC proliferation has not been fully explained. However, our results indicate that the inhibition of the PLC $\gamma 1$ cascade induced by PDGF-BB may be involved in the BST406-induced inhibition of cell proliferation.

In summary, the present study found evidence that BST406 may be useful as an antiproliferation agent and thus as a potential preventive/therapeutic agent in the treatment of 

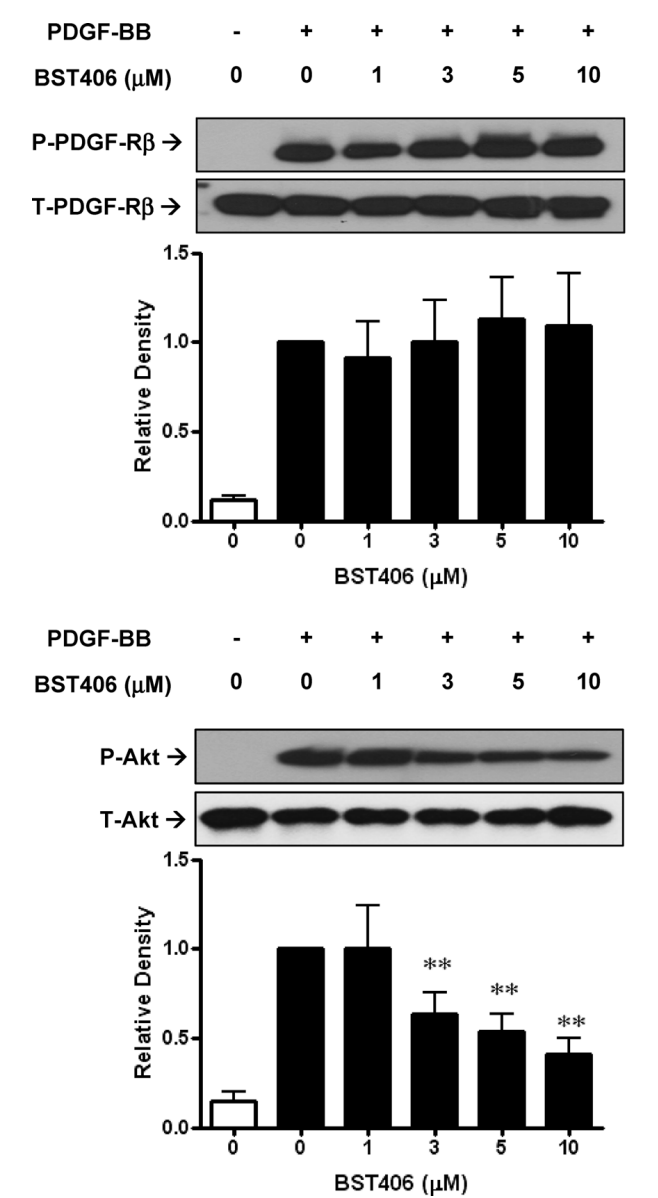
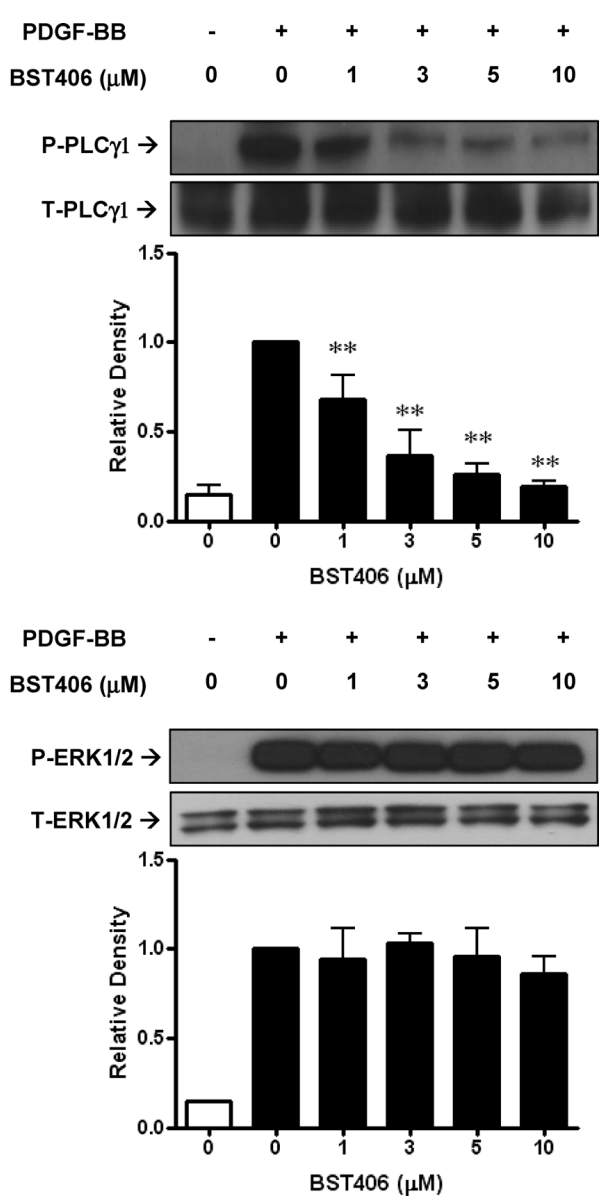

Fig. 3. Effects of BST406 on ERK1/2, Akt, PLC $\gamma 1$, and PDGF-R $\beta$ Phosphorylation in PDGF-BB-Stimulated VSMCs

Cells were cultured in 6-well plates until confluent. The medium was then replaced with serum-free medium in the presence or absence of BST406 ( 0 - $10 \mu \mathrm{M})$ for $24 \mathrm{~h}$. Cells were stimulated with PDGF-BB $25 \mathrm{ng} / \mathrm{ml}$. The cells were then lysed, and proteins from these lysates were analyzed with SDS-PAGE. Quantification of band intensities from three independent experiments was performed using densitometry. Data are presented as mean \pm S.D. from three experiments performed in triplicate for P-PLC $\gamma 1 / \mathrm{T}$-PLC $\gamma 1$, PERK1/2/T-ERK1/2, P-Akt/T-Akt, and P-PDGF-R $\beta /$ T-PDGF-R $\beta$. * $p<0.05, * * p<0.01$ compared with PDGF-BB alone.

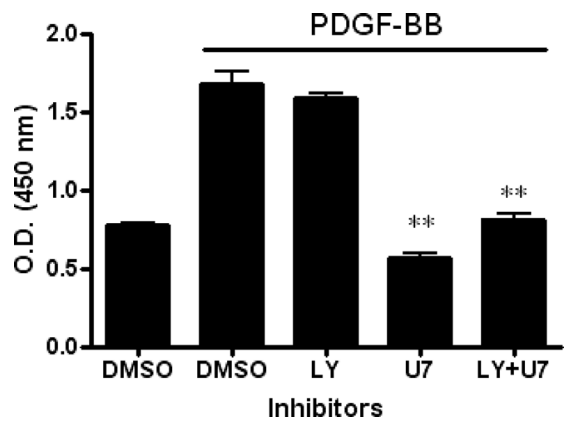

Fig. 4. Effects of Inhibitors on VSMC Viability Following Stimulation with PDGF-BB

Cells were precultured in serum-free medium in the presence or absence of LY294002 or U73122 for $5 \mathrm{~h}$ and then stimulated with PDGF-BB $25 \mathrm{ng} / \mathrm{ml}$. After $23 \mathrm{~h}$, an Ez-Cytox kit was added to the medium, and the cells were incubated for $1 \mathrm{~h}$. The optical density was determined at $450 \mathrm{~nm}$ using a microplate reader. Values represent mean \pm S.D. from three different assays. $* * p<0.01$ compared with PDGF-BB alone. LY: LY294002 (10 $\mu \mathrm{M})$, U7: U73122 $(10 \mu \mathrm{M}), \mathrm{LY}+\mathrm{U} 7: \mathrm{LY} 294002(5 \mu \mathrm{M})+\mathrm{U} 73122$ $(5 \mu \mathrm{M})$.

cardiovascular disease. In addition, among the signaling pathways studied, our data suggest that inhibition of the PLC $\gamma 1$ cascade may be involved in the BST406-induced inhibition of VSMC proliferation.

Acknowledgments This work was supported by the
Korea Science and Engineering Foundation (KOSEF) grant funded by the Korean government (MEST) (No. 20090075604).

\section{REFERENCES}

1) Je H. D., Cha S. J., Jeong J. H., Mol. Cell. Toxicol., 4, $72-77$ (2008).

2) Uchida K., Sasahara M., Morigami N., Hazama F., Kinoshita M., Atherosclerosis, 124, 9-23 (1996).

3) Lim Y., Kim T. J., Jin Y. R., Kim D. W., Kwon J. S., Son J. H., Jung J. C., Avery M. A., Son D. J., Hong J. T., Yun Y. P., J. Pharmacol. Exp. Ther, 321, 648-655 (2007).

4) Heldin C. H., Ostman A., Ronnstrand L., Biochim. Biophys. Acta, 1378, F79-113 (1998).

5) Kim T. J., Lee J. H., Lee J. J., Yu J. Y., Hwang B. Y., Ye S. K., Shujuan L., Gao L., Pyo M. Y., Yun Y. P., Biol. Pharm. Bull., 31, 2073-2078 (2008).

6) Graf K., Xi X. P., Yang D., Fleck E., Hsueh W. A., Law R. E., Hypertension, 29, 334-339 (1997).

7) Pyles J. M., March K. L., Franklin M., Mehdi K., Wilensky R. L., Adam L. P., Circ. Res., 8, 904-910 (1997).

8) Srimal R. C., Dhawan B. N., J. Pharm. Pharmacol., 25, 447-452 (1973).

9) Samaha H. S., Kelloff G. J., Steele V., Rao C. V., Reddy B. S., Cancer Res., 57, 1301-1305 (1997).

10) Huang M. T., Lou Y. R., Ma W., Newmark H. L., Reuhl K. R., Conney A. H., Cancer Res., 54, 5841-5847 (1994).

11) Ohtsu H., Xiao Z., Ishida J., Nagai M., Wang H. K., Itokawa H., Su C. Y., Shih C., Chiang T., Chang E., Lee Y., Tsai M. Y., Chang C., Lee K. 
H., J. Med. Chem., 45, 5037-5042 (2002).

12) Hogale M. B., Dhore N. P., Shelar A. R., Pawar P. K., Oriental J. Chem., 2, 55-57 (1986).

13) Ninomiya Y., Shimma N., Ishitsuka H., Antiviral Res., 13, 61-74 (1990).

14) Murakami S., Kijima H., Isobe Y., Muramatsu M., Aihara H., Otomo S., Baba K., Kozawa M., J. Pharm. Pharmacol., 42, 723 -726 (1990).

15) Oh S., Jang S., Kim D., Han I. O., Jung J. C., Arch. Pharm. Res., 29, $469-475$ (2006).

16) Ahn S. I., Park S. K., Lee M. Y., Youn H. S., Mol. Cell. Toxicol., 5, $141-146$ (2009)

17) Sachinidis A., Locher R., Vetter W., Tatje D., Hoppe J., J. Biol. Chem., 265, 10238-10243 (1990).

18) Kim T. J., Han H. J., Lim Y., Song M. C., Kim J., Hong J. T., Yoo H. S., Pyo M. Y., Hwang B. Y., Lee M. K., Yun Y. P., J. Cardiovasc. Pharmacol., 53, 341-348 (2009).

19) Kim T. J., Jeon J., Jin Y. R., Son D. J., Yoo H. S., Hong J. T., Ryu C. K., Shin H. S., Lee K. H., Yun Y. P., J. Cardiovasc. Pharmacol., 49, $280-286$ (2007).

20) Seo J. M., Kim T. J., Jin Y. R., Han H. J., Ryu C. K., Sheen Y. Y., Kim D. W., Yun Y. P., Eur. J. Pharmacol., 586, $74-81$ (2008).

21) Ross R., Nature (London), 362, 801-809 (1993).
22) Kanno Y., Kuroki A., Minamida M., Kaneiwa A., Okada K., Tomogane K., Takeuchi K., Ueshima S., Matsuo O., Matsuno H., Thromb. Res., 123, 336-341 (2008).

23) Kim J. E., Kang Y. J., Lee K. Y., Choi H. C., Biol. Pharm. Bull., 32, 1047-1052 (2009).

24) Jin Y. R., Han X. H., Zhang Y. H., Lee J. J., Lim Y., Kim T. J., Yoo H. S., Yun Y. P., J. Cell. Biochem., 104, 1-14 (2008).

25) Kim T. J., Yun Y. P., Vascul. Pharmacol., 46, 43-51 (2007).

26) Muller D. W., Prog. Cardiovasc. Dis., 40, 117-128 (1997).

27) Claesson-Welsh L., J. Biol. Chem., 269, 32023-32026 (1994).

28) Higaki M., Shimokado K., Arterioscler. Thromb. Vasc. Biol., 19, 2127-2132 (1999).

29) Waltenberger J., Circulation, 96, 4083- 4094 (1997).

30) Myllärniemi M., Frösen J., Calderón Ramirez L. G., Buchdunger E., Lemström K., Häyry P., Cardiovasc. Drugs Ther., 13, 159-168 (1999).

31) Kim T. J., Han H. J., Hong S. S., Hwang J. H., Hwang B. Y., Yoo H. S., Jin Y. R., Lee J. J., Yu J. Y., Lee K. H., Kang B. W., Yun Y. P., Biol. Pharm. Bull., 30, 805-809 (2007).

32) Lipson K. E., Pang L., Huber L. J., Chen H., Tsai J. M., Hirth P., Gazit A., Levitzki A., McMahon G., J. Pharmacol. Exp. Ther., 285, 844 852 (1998). 